\title{
The Pro-Inflammatory Response of Macrophages During Dental Implant with the Help of Titanium Surface Coating Modulates
}

\author{
Dr. Shahzada Faiz Ahmad Khan ${ }^{1}$, Dr. Zeeshan Irshad ${ }^{2}$, Dr. Ahmad Naeem Orakzai ${ }^{3}$ \\ Dr. Furqan Jamal ${ }^{4}$ \\ ${ }^{1}$ RHC Qadirabad, Dera Ghazi Khan \\ ${ }^{2}$ DHQ Rajanpur \\ ${ }^{3}$ Agency Headquarter (AHQ), Misthi Mela, Orakzai Agency \\ ${ }^{4}$ RHC 96/12-L, Tehsil Chichawatni, District Sahiwal \\ ahmad.afghan56@gmail.com
}

\begin{abstract}
Introduction: The use of titanium plates in dental implants has revolutionized the oral health care in last few decades. Extensive work has been done to justify the use of titanium as a metal of choice for dental surgical interventions but the mechanism explaining its biocompatible properties has not been elucidated yet.

Material and methods: In this study we aimed at exploring the role titanium surface coating with calcium phosphate and physical vapors depositing in the modulation of pro-inflammatory cytokines particularly TNF-alpha (TNF $\alpha$ ) and IL-1beta (IL-1 $\beta$ ) and chemokines MCP1/CCL2. Human macrophages cell line (THP-1) was used to compare the effect of CaP and PVD coating onto the titanium plates.

Results: We characterized the surface topography of titanium plates with X-ray photoelectron spectroscopy. Macrophage attachment and proliferation was assessed using an MTT assay. The expression of pro-inflammatory cytokines TNF- $\alpha$, IL 1- $\beta$ and Ccl- 2 chemokines MCP- 1 by adherent THP-1 cells was assessed by real time PCR after $24 \mathrm{~h}$ culture on either smooth non coated (NC), smooth coated with calcium phosphate (CaP), or smooth with physical vapors deposited (PVD) titanium surfaces. The results showed significant down- regulation of TNF- $\alpha$ and IL- $\beta$ while up-regulation of chemokines MCP1/CCL2 in macrophages cultured onto the both CaP coated and PVD coated surfaces. No significant difference was observed in the level of cellular attachment or proliferation of THP-1 cells to the different titanium surfaces. We hypothesize that the down-regulation of pro-inflammatory cytokine genes expression possibly modulate the inflammatory response and may facilitate the enhanced bone wound healing after titanium implantation.
\end{abstract}

Key words: inflammatory, response, macrophages.

INTRODUCTION

Bone-anchored titanium implants have been extensively used in medical surgical procedures such as internal orthopaedic fixation, body devices, and dental implants. Now days, titanium is considered as a metal of choice for such surgical interventions. This is due to the fact that titanium has been proved as the most biocompatible metal; as it could endure the attack of the body fluids, resides inert inside the body, well-suited to bone growth, flexible, and strong. Titanium performs all these functions due to protective oxide film formation that is produced naturally in the presence of oxygen oxide.

The incorporation of titanium implant in the human body provokes a cascade of healing processes and host responses collectively known as inflammation \{Anderon JM, et al, 1993\}. Briefly, implant placement is followed by: clot formation, adsorption of serum components, the migration and attachment of undifferentiated 
The Pro-Inflammatory Response of Macrophages During Dental Implant with the Help of Titanium Surface Coating Modulates

mesenchymal cells onto the implant surface, their proliferation and differentiation \{park et al, 2001\}. However, the healing process around implants is mainly determined by macrophages as their actions take place before the undifferentiated mesenchymal cells reach to the wound site. In fact, macrophages may control the response of the mesenchymal cells \{Willert HG et al, 1977, Howje DW et al, 1990, Neale SD et al, 2000\}.

Macrophages are produced by the differentiation of monocytes in tissues and are dominant phagocytes at sites of wound healing and inflammation. In fact they are the first cells to reach the site of implant/wound \{Hamlet $\mathrm{S}$ et al, 2012\}. They engulf and then digest (phagocytosis) foreign substances, cellular debris infectious microbes, and cancer cells and pathogens. In addition to the phagocytosis, macrophages play a vital role in both non-specifics (innate) as well as in specific defense mechanisms (adaptive). They have also been reported to stimulate immune cells including lymphocytes and to respond to pathogens \{Davies JE et al, 2003\}. Macrophages interaction with implants leads to the secretion of pro-inflammatory cytokines and chemokines \{Teedgiu et al 2006\}. Indeed, pro-inflammatory cytokines and chemokines are mainly secreted by macrophages already present at the wound site attract the monocyte to the wound site. In addition, macrophages have been reported to modulate the early phase of the inflammatory process through the release of a wide array of cytokines and chemokines that influence the behavior of other cellular events.

Although plenty of cytokines and chemokines are implicated in reparative stages of early wound healing after insertion of the implant, proinflammatory cytokines including interleukin IL-1alpha, tumor necrosis factor-alpha $(\mathrm{TNF} \alpha$ ), and chemokines such as monocyte chemo attractant protein (MCP-1) (also called CCL2) are widely expressed at the early stages of implantation. These two cytokines are known to induce an inflammatory response during the early stage of the healing process. Their secretion direct host responses for instance cellular recruitment and bone formation. These have also been shown to play a vital role in the bone wound healing by influencing mesenchymal stem cell recruitment and differentiation, over and above osteoclast migration and differentiation \{ Kindle L et al, 2006, Nakahama K et al, 2010\}. Similarly, chemokine included in the study, CcL2/ MCP-1 has a key role in immunoregulatory and inflammatory processes as well as in tissue repair.

In fact, in titanium implants, the roughness in micrometer plays an important role in modulating the cellular response \{Albekston $\mathrm{T}$ et al, 2004\}. However, it not yet clear that which coating favor most the wound healing and osteointegration as there is little information about the effect of titanium modification on macrophage function in a non-phagocytosable model

\section{OBJECTIVES}

The aim of the present study was to compare the effects of titanium surface coating including calcium phosphate (CaP) and physically vapors deposited (PVD) coating on the macrophages attachment, proliferation, and cytokines and chemokines secretions in particular pro-inflammatory chemokine monocyte chemo attractant protein-1 (MCP-1) and cytokines including tumour necrosis factor- $\alpha$ (TNF- $\alpha$ ) and interleukin IL-1 $\beta$ secretion by macrophages.

\section{MATERIALS AND METHOdS}

\section{Titanium Implants}

We used commercially available pure titanium discs (Ti-CP-GRD4) with $1 \mathrm{~mm}$ thickness ad $15 \mathrm{~mm}$ diameter. For calcium coating surfaces, nanoscale calcium phosphate (CaP)-modified (Nano Tite_, Biomet 3i, Palm Beach Gardens, FL) were used in the study. Physical vapors were deposited on the same commercially available pure titanium discs. These three titanium plates were named as non coated (NC), titanium plate coated with calcium phosphate (CaP), and physically vapors deposited (PVD). Before starting the experimental manipulation, we examined the topography and composition of each surface with X-ray photoelectron spectroscopy (XPS; FEI Quanta 200 Environmental SEM). 
The Pro-Inflammatory Response of Macrophages During Dental Implant with the Help of Titanium Surface Coating Modulates

\section{Cell Culture}

A total number of $5^{*} 10^{4} /$ per well of human macrophages cells (THP-1) were cultured onto the three described titanium discs in 24-well tissue culture plates (Falcon, Lincoln Park, NJ) in triplicate for 72h in RPMI 1640 medium (Gibco, Grand Island, NY) supplemented with 1\% penicillin/streptomycin (Cambrex BioScience, Walkersville, MD) and 10\% heat-inactivated calf serum (Serum supreme). The cells were incubated at $37 \mathrm{C}^{0}$ in a humid environment with 5\% CO2 atmosphere.

\section{Cellular Proliferation and Attachment}

We measured the effect of surface topography on cellular proliferation and attachment after $72 \mathrm{~h}$ of incubation. Briefly, $5^{*} 10^{4}$ human macrophages THP-1 cells were cultured onto the three described titanium discs in 24-well tissue culture plates in triplicate. At the end of $72 \mathrm{~h}$, the effect of surface coating on cellular proliferation and attachment was determined using an MTT-based kit (Sigma, Saint Louis, MO), by following the manufacturer instructions.

\section{RNA Extraction and Cytokine Measurement}

Total RNA was extracted (Ambion RNaqueous-4pcr) at the end of experimental period and synthesized complementary DNA (cDNA) according to the manufacturer's instructions (Fermentas, USA). We performed quantitative analysis of mRNA expression of mentioned inflammatory cytokines and chemokines with the RealTime PCR using TM SYBR Green PCR master mix (SA Biosciences, Frederick, MD, USA). The mRNA values were normalized to GAPDH values and expressed in term of Fold-changes. The primers used for the gene expression of the TNF $\alpha$, IL-1 $\beta$, CCL2/MCP-1, and GAPDH are mentioned in the Table 1.

Table1. Real time primer sequences used for cytokines and chemokines

\begin{tabular}{|l|l|l|}
\hline Primer & Forward & Reverse \\
\hline TNF $\alpha$ & 5'-GGAGAAGGGTGACCGAC-3' & 5'-CTGCCC CTCGGCAA-3' \\
\hline IL-1 $\beta$ & 5'-AATCTGTACCTGTCCTGCG-3' & 5'GGGTAATTTTTGGGATCTAC-3' \\
\hline MCP-1 & 5'-ACTCTCGCCTCCAGCATGAA-3' & 5'TTGATTGCATCTGGCTGAGC-3' \\
\hline GAPDH & 5'-TGCACCACCAACTGCTT-3' & 5'-GGCATGGACTGTGGTCAT-3' \\
\hline
\end{tabular}

Enzyme linked Immunosorbent Assay (ELISA)

The THP- 1 cells $\left(0.5 \times 10^{5}\right.$ cells/well of 24 -well plates $)$ were seeded in EPILIFE growth medium (R\&D), containing three mentioned titanium plates for 24,48 , and $72 \mathrm{~h}$ at $37^{\circ} \mathrm{C}$. Medium alone was used as a negative control. After each time point, supernatant was harvested and IL-alpha levels were measured using the Quantikine (R\&D Systems, Minneapolis, MN) and DuoSet ELISA kits (R\&D Systems), following the manufacturer's protocols.

\section{Statistical Analysis}

We performed the X-ray compositional analysis (XPS) of the titanium discs at three different occasions. We performed three replicate experiments for the cell proliferation and attachment studies which yielded comparable results. Significance was assessed by analysis of variance. All p-value less than 0.05 were considered as statistical significance. For the gene expression of cytokines and chemokines, three experiments were performed in triplicate and student's $t$ test was applied to check the statistical significance of the obtained data. $p$ values $<0.05$ and $>$ than 0.01 were considered significant and indicated with $*$, p values $<0.01$ were considered highly significant and indicated with asterics $\left(^{* *}\right)$. Error bars in the graphs represent the standard deviation (SD).

\section{RESULTS}

\section{Titanium Surface Analysis}

First, we performed the surface elementary analysis of all titanium discs. XPS analysis showed that all titanium plates contain the similar level of carbon contamination (mean of 16.92\%). The nanoscale medication with 
The Pro-Inflammatory Response of Macrophages During Dental Implant with the Help of Titanium Surface Coating Modulates

calcium and PVD coating reduced the titanium concentration (31.7\%) compared to the smooth non coated titanium plates. However the nanoscale modification leads to the high calcium and phosphorus contents as shown in Table 2. Shortly, Oxygen contents were higher for calcium coated plates while increase in the nitrogen contents was observed for PVD coating.

Table2. Composition (elementary) of titanium disc surfaces

\begin{tabular}{|l|l|l|l|l|l|l|}
\hline Surface & Oxygen & Carbon & Nitrogen & Titanium & Calcium & Phosphorus \\
\hline NCPO & 43.32 & 21.50 & 71.09 & 31.91 & 0.20 & - \\
\hline Cap & 52.82 & 18.05 & - & 12.95 & 11.42 & 4.91 \\
\hline PVD & 49.53 & 19.44 & 41.34 & 19.45 & - & - \\
\hline
\end{tabular}

Atomic analysis (mean $\% \pm$ SEM) of elements detected by XPS survey for each of the titanium plates. NC; non-coated, CaP: calcium coated pure titanium, PVD: physically vapor deposited.

\section{THP-1 Cells Attachment and Cell Proliferation}

We speculated, the changes in cytokine and chemokines secretions could be the results of cells attachment and proliferation ability. Thus, we aimed to measure the proliferation and attachment rate of THP-1 cell onto the surface of coated and non-coated titanium plates. By using MTT assay, we compared THP-1 cells proliferation after 24 and $72 \mathrm{~h}$ incubation on each of the titanium surfaces. Interestingly, a significant increase in the proliferation of THP-1 cells was observed when cultured on all three titanium surfaces for $72 \mathrm{~h}$ not for $24 \mathrm{~h}$. However, no significant difference in term of proliferation was observed among different titanium surfaces, though proliferation was higher for cell cultured $\mathrm{n}$ the $\mathrm{CaP}$ coated titanium plates (Figure 1). On the same time, we also examined the attachment of THP-1 on three different surfaces at 1, 2 and $3 \mathrm{~h}$ time points. Similar to proliferation pattern, no difference was observed among three surfaces but slight increase in attachment was observed after 3 hours (Figure 2). In conclusion, the results demonstrated that changes of topography in the titanium do not alter the proliferation and attachment ablilities of the macrophages.

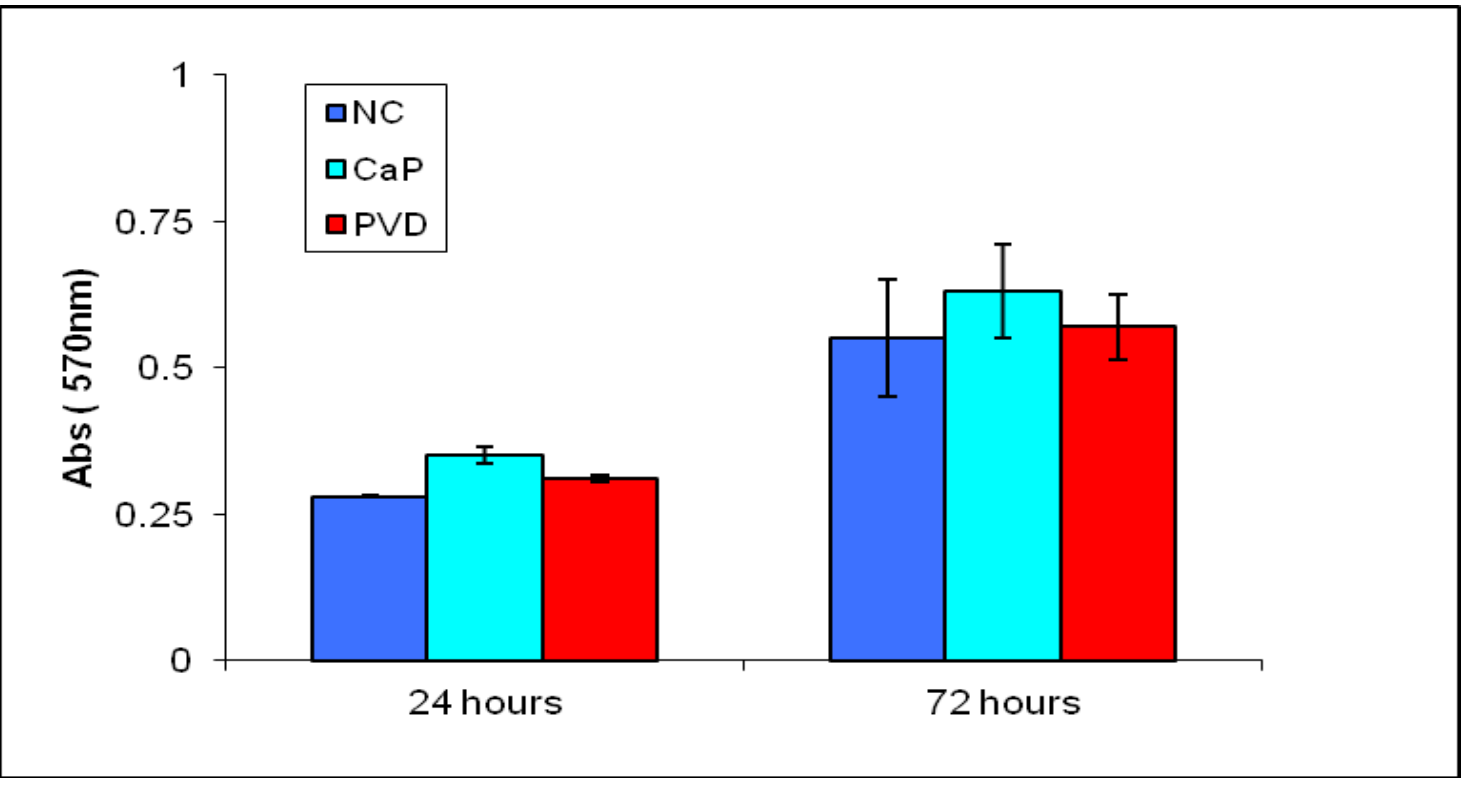

Figure1. THP-1 cells Proliferation after 24 and $72 \mathrm{~h}$ culture on three different titanium surfaces. Proliferation augmented significantly $(p=0.005)$ after 72 h on all titanium surfaces. Proliferation rate does not vary significantly at either time point among the titanium surface topographies. Surfaces: NC; non-coated, CaP: calcium coated pure titanium, PVD: physically vapor deposited. 
The Pro-Inflammatory Response of Macrophages During Dental Implant with the Help of Titanium Surface Coating Modulates

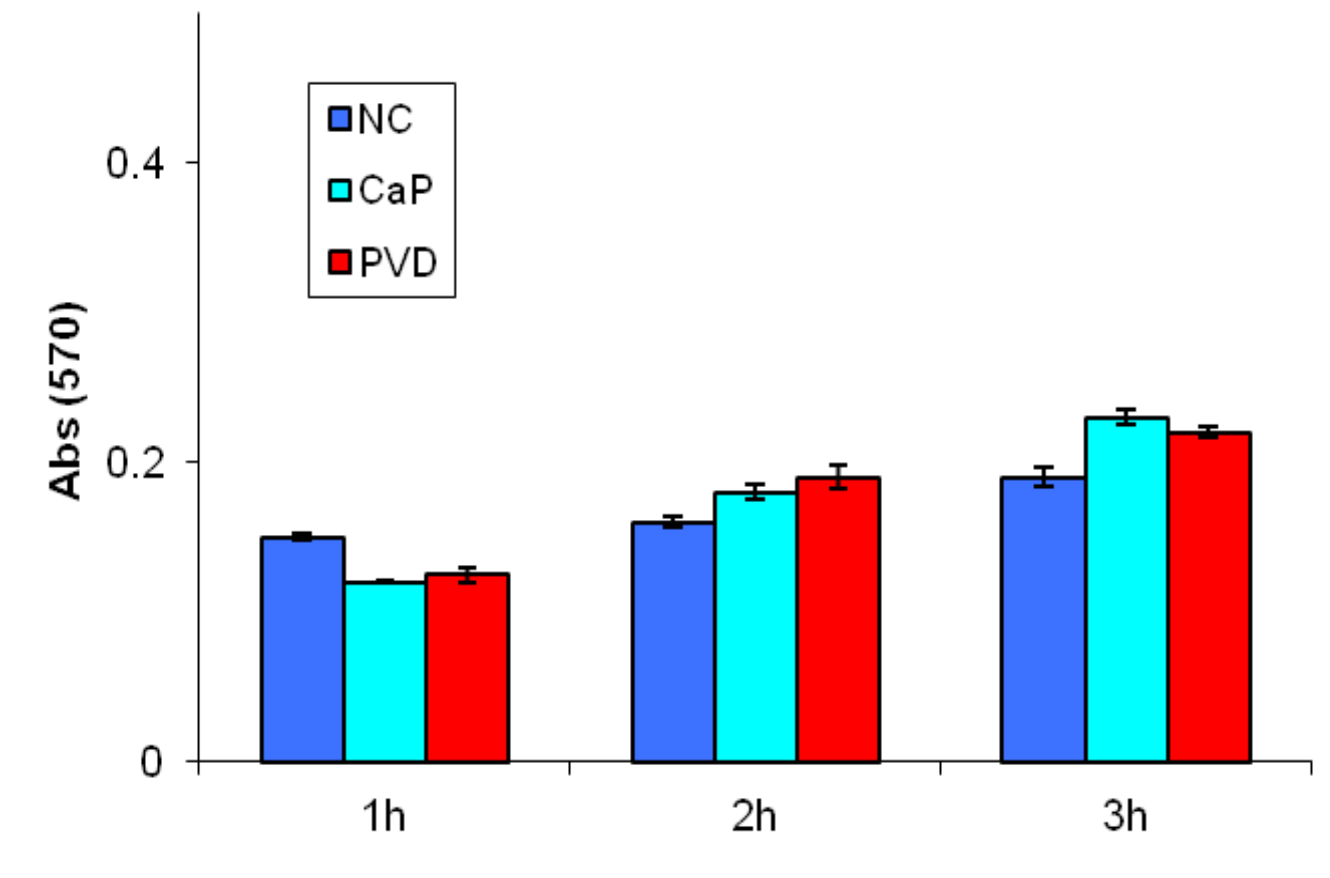

Figure2. Attachment of THP-1 cells after 1,2 and 3h culture on three different titanium plates. No significant difference was observed at any time point among three titanium surface topographies. However, a non significant small increase in attachment with increasing culture time was observed. Surfaces: NC; non-coated, CaP: calcium coated pure titanium, PVD: physically vapor deposited.

\section{Cytokines and Chemokines Secretions}

Previous studies have described that surface topography of the titanium implants influence the inflammatory response to the titanium implants \{Ding T et al, 2009\}. Therefore, we sought to measure the secretion of cytokines by THP-1 cells cultured on three different titanium implants for 72 hours. We choose $72 \mathrm{~h}$, as no difference wad at earlier time points in term of proliferation and attachment. The real time PCR results shown that TNF $\alpha$ and IL-1 $\beta$ levels were strongly down regulated in macrophages grown on the CaP and PVD surfaces (Figure 3A and 3B). However the degree of down regulation was more pronounced in CaP treated titanium implants than the PVD coated titanium plates. Moreover, the reduction in the fold changes for the expression level of IL-1 $\beta$ was higher than the TNF $\alpha$ levels. On the other hand, the secretion level of MCP-1/CCL2 was statically higher in the $\mathrm{CaP}$ and PVD coated titanium implants in comparison to the non coated ones (Figure 3C). In order to strengthen our result for changes in the cytokines levels, we performed ELISA for the IL-1 $\beta$ secreted levels after 24, 48, $72 \mathrm{~h}$ in macrophages grown in the three different cultured systems. Interestingly, data obtained from ELISA confirmed real time PCR results showing that the levels of IL-1 $\beta$ go down immediately after implants have placed in the vivo system (Figure 4). Altogether, these results demonstrate that the macrophage cytokines and cheokines gene expression is directing the inflammatory process towards a less pro-inflammatory macrophage phenotype, in response to the CaP and PVD coated titanium surface. 
The Pro-Inflammatory Response of Macrophages During Dental Implant with the Help of Titanium Surface Coating Modulates

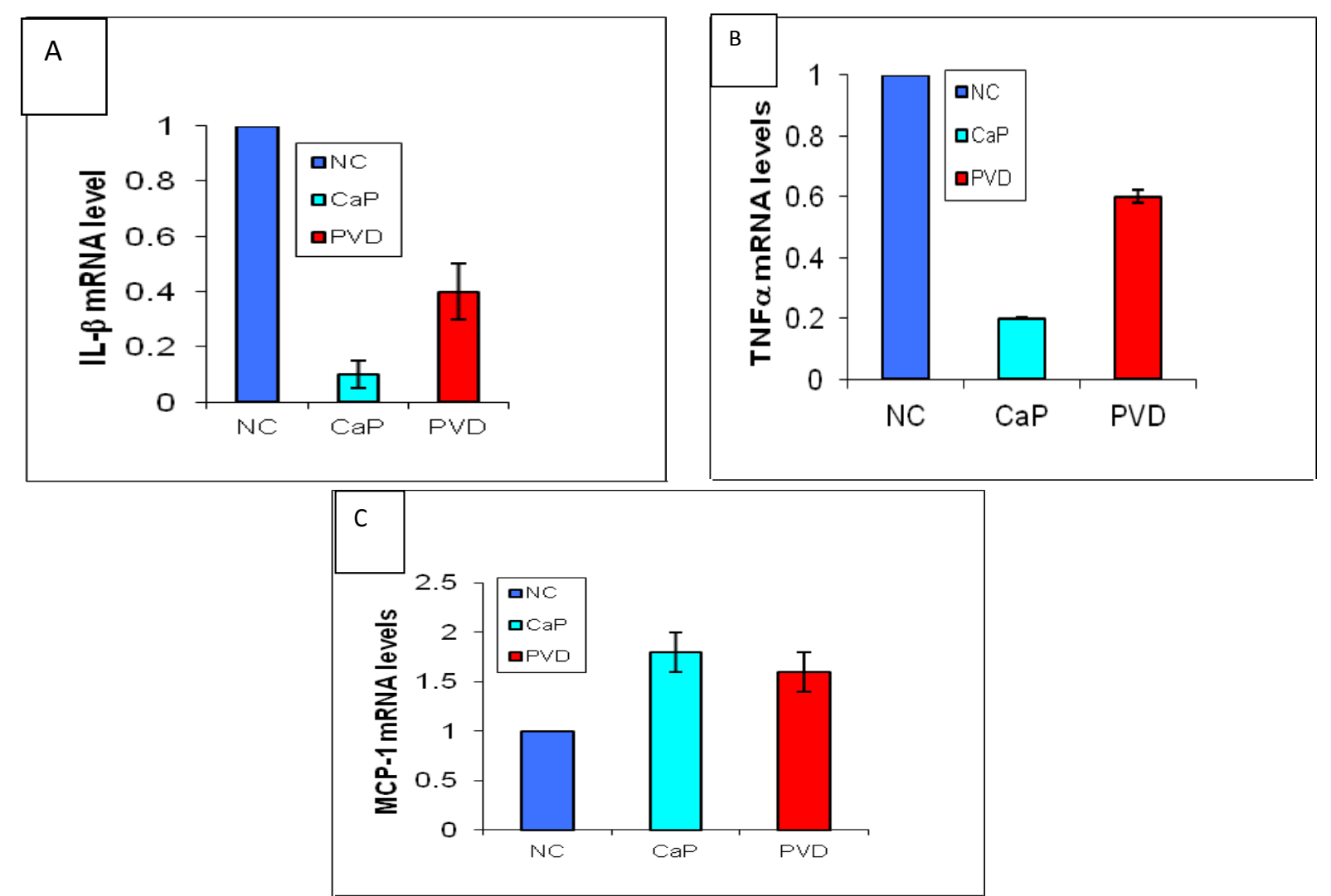

Figure3. $m R N A$ levels of secreted cytokines and chemokines from THP-1 cells on three different titanium surfaces after 72h. $(A, B, C)$ Figures shows the down-regulation of TNF $\alpha$ and IL-1 $\beta$ while up-regulation of MCP-1 in macrophages cultured on the CaP and PVD coated surface. Surfaces: NC; non-coated, CaP: calcium coated pure titanium, PVD: physically vapor deposited.

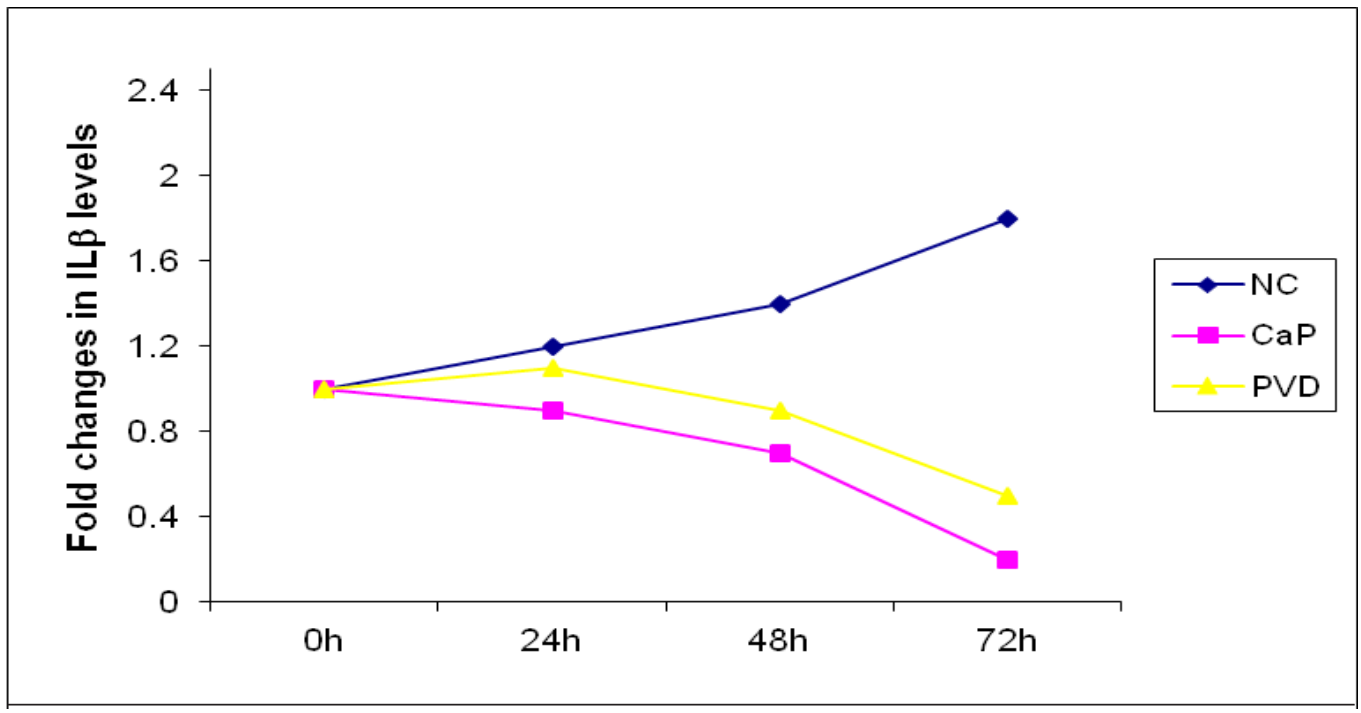

Figure4. Measurement of IL-1 $\beta$ secreted levels in macrophages cultured on three different titanium plates for 24 , 48, and 72 hours. Surfaces: NC; non-coated, CaP: calcium coated pure titanium, PVD: physically vapor deposited. 
The Pro-Inflammatory Response of Macrophages During Dental Implant with the Help of Titanium Surface Coating Modulates

\section{DISCUSSION}

Titanium plates are regularly used for the surgical interventions particularly in dental implants. In the beginning, only smooth titanium implants have been used while latter on, surface topography have been modified in various ways. Interestingly, such topographical modifications have improved the implant success rate as well as hastened the wound healing process. It has already been well established that cells preferably grow well on the rough surfaces in comparison to the smooth surfaces \{Wojciak-Stothard B et al, 1995\}. However, differences have also been observed among different smooth surfaces, coated and non coated and even in between coated surfaces. For instance, in one study, calcium phosphate has been shown to reach superior bone wound healing and osseointegration compared with smooth titanium surface \{Albekston $\mathrm{T}$ et al, 2004\}. The present study was aimed to compare the effects of titanium surface coating such as calcium phosphate (CaP) and physically vapors deposited (PVD) coating on the macrophages attachment, proliferation, and cytokines and chemokines secretions in particular pro-inflammatory chemokine monocyte chemo attractant protein-1 (MCP-1) and cytokines including tumor necrosis factor- $\alpha$ (TNF- $\alpha$ ) and interleukin IL-1 $\beta$ secretion by macrophages.

The results of the presentstudy demonstrate that the surface coating of the non-phgocytosable titanium implantes can modify the secretion of TNF $\alpha$, IL-1 $\beta$ and MCP- 1 from the macrophages. However, no significant difference was observed in these macrophages in term of proliferation and attachment. It is highly promising that these effects on macrophages form part of the basis for the successful and rapid development of osseointegration in implants with coated surfaces with no demonstrable effect on macrophage attachment or proliferation.

Activation of the macrophages by nanomodified Cap and PVD coated surfaces resulted in the statistically significant down-regulation of pro-inflammatory cytokines TNF $\alpha$ and IL-1 $\beta$ and statistically significant increase in the chemokine MCP-1. Subsequently, the down-regulation of the IL-1 $\beta$ was further confirmed by using ELISA measuring the secreted IL-1 $\beta$ at different time points. The dwon-regulation of proinflamatory cytokines and up-regulation of MCP-1 are due to surface coating of titanium plates with calcium and vaporaisation. However, on the same time the possible contribution of the chemical composition of the titanium implants can be entirely ruled out. Interestingly, similar results have been described in Sethi RK et al, 2003 study, where materials-dependent modification in the mRNA expression of the pro-inflammatory cytokines TNF-alpha and IL-1beta has been shown in two cell lines; RAW 264.7 cell line and human peripheral blood monocyte cultures \{Sethi RK et al, 2003\}.

The down-regulation of these two key inflammatory cytokines might have highly significance in wound healing and other inflammatory processes. TNF $\alpha$ plays an essential role in regulating the bone formation and repair \{Gerstenfeld LC et al, 2001\}. It has described that TNF $\alpha$ negatively regulates the bone formation in the rat growth plate and its reticence decreases mesenchymal and osteoprogenitor cell infiltration but increases bone formation \{Zhou FH et al, 2006\}. Although, less number of mesenchymal cells reach to site of impanation but the ones recruited they are more like osteoblast in morphology and in a more differentiated stage.

It has also been described in the literature that the inflammatory cytokines TNF- alpha and IL-1 $\beta$ regulate the expression of certain chemokines such as CCL2, CCL5 and CCL8 \{Ding T et al, 2009 and Yaszay B et al 2001\}. Moreover, they mediate the regulation of cell differentiation, proliferation and tissue homeostasis \{Le Yet al $2004\}$. We wonder that the up-regulation of MCP-1couldalso be linked with the down-regulation of IL-1 $\beta$ and TNF-alpha. Thus further studies are required to rule out this possibility.

Our study showing up-regulation of MCP-1 in CaP coated surface as well as in PVD confirms the idea that wound healing occur more rapidly in the coated surfaces than the non-coated ones. In fact, it has already been described that the induction of MCP-1 expression in RAW 264.7 cells play a vital role in bone resorption by stimulating 
The Pro-Inflammatory Response of Macrophages During Dental Implant with the Help of Titanium Surface Coating Modulates

chemotactic recruitment and RANKL-mediated differentiation of pre-osteoclasts and increasing the migration of mature osteoclasts to new sites of bone resorption\{Yu X et al, 2004\}.

Taken together, these results indicate that the macrophage cytokine gene expression profile is directing the inflammatory process towards a less pro-inflammatory macrophage phenotype, in response to the titanium surface coating. This tendency towards an attenuated pro-inflammatory macrophage phenotype by the titanium surface coating is likely to influence downstream healing events via the macrophage releasate and increase the healing process.

\section{REFERENCES}

1. Albekston T and Wennerberg A. 2004. Oral implants surfaces: part 1-review focusing on topographic and chemical properties of different surfaces and in vivo responses to them. Int. J. Prosthodont. 17, 536 -543.

2. Anderson JM. Mechanism of inflammation and infection with implanted devices. Cardiovasc Pathol 1993;2(3 Suppl):33S- 41S.

3. Berglundh T, Abrahamsson I, Lang NP, Lindhe J. De novo alveolar bone formation adjacent to endosseous implants. Clin Oral Implants Res 2003; 14(3):251-62.

4. Boyan, B., Dean, D., Lohmann, C., Cochran, D., Sylvia, V. \& Schwartz, Z. 2001 The titanium-bone cell interface in vitro: the role of the surface in promoting osteointegration.

5. Buser D, Nydegger T, Hirt HP, Cochran DL, Nolte LP. Removal torque values of titanium implants in the maxilla of miniature pigs. Int J Oral Maxillofac Implants 1998; 13:611-9.

6. Cochran DL, Schenk RK, Lussi A, Higginbottom FL, Buser D. Bone response to unloaded and loaded titanium implants with a sandblasted and acid-etched surface: a histometric study in the canine mandible. J Biomed Mater Res 1998;40(1):1-11.

7. Davies JE. Understanding peri-implant endosseous healing. J Dent Educ 2003;67:932-949.

8. Ding T, Sun J, Zhang P. Study on MCP-1 related to inflammation induced by biomaterials. Biomed Mater 2009;4(3):35005.

9. Gerstenfeld LC, Cho TJ, Kon T, Aizawa T, Cruceta J, Graves BD, et al. Impaired intramembranous bone formation during bone repair in the absence of tumor necrosis factor-alpha signaling. Cells Tissues Organs 2001; 169(3):285-94.

10. Hamlet S, Alfarsi M, George R, Ivanovski S. The effect of hydrophilic titanium surface modification on macrophage inflammatory cytokine gene expression. Clin Oral Implants Res 2012; 23:584-590.

11. Howie DW. Tissue response in relation to type of wear particles around failed hip arthroplasties. J Arthroplasty 1990; 5(4):337-48.

12. In Titanium in medicine (eds D. M. Brunette, P. Tengvall, M. Textor \& P. Thomsen), pp. 561-585. New York, NY: Springer

13. Junker, R., Dimakis, A., Thoneick, M. \& Jansen, J. A.2009 Effects of implant surface coatings and composition on bone integration: a systematic review. Clin. Oral Implants Res. 20, 185-206. (doi:10.1111/j.1600-0501. 2009.01777 .

14. Kindle L, Rothe L, Kriss M, Osdoby P, Collin-Osdoby P. Human microvascular endothelial cell activation by IL-1 and TNF-alpha stimulates the adhesion and transendothelial migration of circulating human CD14+ monocytes that develop with RANKL into functional osteoclasts. J Bone Miner Res 2006;21(2):193-206.

American Research Journal of Dentistry

Page 46 
The Pro-Inflammatory Response of Macrophages During Dental Implant with the Help of Titanium Surface Coating Modulates

15. Le Y, Zhou Y, Iribarren P, Wang J. Chemokines and chemokine receptors: their manifold roles in homeostasis and disease. Cell Mol Immunol 2004;1(2):95-104.

16. Nadra I, Boccaccini AR, Philippidis P, Whelan LC, McCarthy GM, Haskard DO, et al. Effect of particle size on hydroxyapatite crystal-induced tumor necrosis factor alpha secretion by macrophages. Atherosclerosis 2008; 196(1):98-105.

17. Nakahama K. Cellular communications in bone homeostasis and repair. Cell Mol Life Sci 2010; 67(23):4001-9.

18. Neale SD, Haynes DR, Howie DW, Murray DW, Athanasou NA. The effect of particle phagocytosis and metallic wear particles on osteoclast formation and bone resorption in vitro. J rthroplasty 2000;15(5):654-62.

19. Park JY, Gemmell CH, Davies JE. Platelet interactions with titanium: modulation of platelet activity by surface topography. Biomaterials 2001; 22(19):2671-82.

20. Raines, Andrew L.; Olivares-Navarrete, Rene; Wieland, Marco; Cochran, David L.; Schwartz, Zvi; Boyan, Barbara D. (2010). "Regulation of angiogenesis during osseointegration by titanium surface microstructure and energy". Biomaterials31 (18): 4909-17.

21. Sethi RK, Neavyn MJ, Rubash HE, Shanbhag AS. Macrophage response to cross linked and conventional UHMWPE. Biomaterials 2003;24(15):2561-73.

22. Tedgui, Z. Mallat, Cytokines in atherosclerosis: pathogenic and regulatory pathways, Physiol. Rev. 86 (2006) 515-581.Thomsen P, Gretzer C. Macrophage interactions with modified material surfaces. Curr Opin Solid State Mater 2001; 5:163-176.

23. Willert HG, Semlitsch M. Reactions of the articular capsule to wear products of artificial joint prostheses. J Biomed Mater Res 1977; 11(2):157-64.

24. Wojciak-Stothard B, Madeja Z, Korohoda W, Curtis A, Wilkinson C. Activation of macrophage-like cells by multiple grooved substrata. Topographical control of cell behaviour. Cell Biol Int 1995; 19(6):485- 490.

25. Yaszay B, Trindade MC, Lind M, Goodman SB, Smith RL. Fibroblast expression of C-C chemokines in response to orthopaedic biomaterial particle challenge in vitro. J Orthop Res 2001; 19(5):970-6.

26. Yu X, Huang Y, Collin-Osdoby P, Osdoby P. CCR1 chemokines promote the chemotactic recruitment, RANKL development, and motility of osteoclasts and are induced by inflammatory cytokines in osteoblasts. J Bone Miner Res 2004;19(12):2065-77.

27. Zhou FH, Foster BK, Zhou XF, Cowin AJ, Xian CJ. TNF-alpha mediates p38 MAP kinase activation and negatively regulates bone formation at the injured growth plate in rats. J Bone Miner Res 2006;21(7):1075-88.

Citation: Dr. Shahzada Faiz Ahmad Khan, Dr. Zeeshan Irshad, Dr. Ahmad Naeem Orakzai, Dr. Furqan Jamal, "The Pro-Inflammatory Response of Macrophages During Dental Implant with the Help of Titanium Surface Coating Modulates". American Research Journal of Dentistry; 1(1): 39-47.

Copyright (c) Dr. Shahzada Faiz Ahmad Khan, Dr. Zeeshan Irshad, Dr. Ahmad Naeem Orakzai, Dr. Furqan Jamal, This is an open access article distributed under the Creative Commons Attribution License, which permits unrestricted use, distribution, and reproduction in any medium, provided the original work is properly cited. 